\title{
Attitudes of the Female University Students towards Skin Whitening in Bangladesh
}

\section{Md Moyazzem Hossain*}

Department of Statistics, Jahangirnagar University, Bangladesh

*Corresponding author: Moyazzem Hossain MD, Department of Statistics, Jahangirnagar University, Savar, Dhaka-1342, Bangladesh, Tel: +880-1716-657066; Email: mmhmm.justat@ gmail.com

\section{Research Article \\ Volume 4 Issue 1}

Received Date: November 29, 2019

Published Date: January 17, 2020

DOI: $10.23880 /$ eij-16000134

\section{Abstract}

Aim: This paper attempts to examine the attitude of female students towards skin whitening products.

Method: Nowadays, due to the aggressive Internet and print media advertising, skin whitening products are growing. Therefore, for finding the attitude, knowledge, practice, and perception of the female students about skin whitening, a selfadministered questionnaire was used to collect the primary data from the respondents. Descriptive statistics were employed to analyze the gathered data.

Results: Among the respondents, 30 percent of students agreed that the use of skin whitening products is a good practice. However, about 40 percent of respondents had a skin problem due to the use of such products. Moreover, more than threequarter of the respondents having a perception that their counterpart considers them with lighter skin to be more beautiful. Also, another three important factors are lighter skin increase the likelihood of getting married, look healthier and provide higher self-esteem.

Conclusion: Several factors are responsible to increase the skin whitening products like look beautiful, likelihood of getting jobs as well as marriage. However, due to the use of different skin whitening products, female students sometimes suffered from several skin diseases.

Keywords: Skin whitening; University Student; Bangladesh

\section{Introduction}

Skin whitening is one kind of cosmetic treatment where chemical materials are used to lighten the skin tone by reducing the concentration of melanin. Melanin is responsible for a person's skin color which is a type of pigment created in the melanocyte cells. Skin lightening has a long history in many parts of the world. In the past, many women fabricated their own mixture to lighten their skins. There are different ways to lighten the skin complexion and among them, the most common methods are laser treatment, the usage of skin whitening products like creams, lotions and soaps. Actually, skin whitening/lightening is a very old practice, which is now global in scope. However, due to the aggressive Internet and print media advertising, skin whitening products and antiaging cosmetics are now growing and becoming profitable markets [1]. In some cultures, a light complexion is not only the symbol of beauty but also related to marital opportunities, job opportunities and social status [2]. However, darker skin is much more beneficial to one's health because it has protection pigment that fights against the ultraviolet rays of the sun. Nevertheless, the use of skin whitening/lightening products growing all over the world [3]. Among the ingredients used in skin whitening creams, some appeared to be effective in skin whitening, while others may be the reason for skin damage. Some of the chemicals used in skin 


\section{Epidemiology International Journal}

products having negative side effects like irritation. However, Hindustan Lever Limited (HLL) claims that its products do not contain dangerous chemicals like some other skin whitening creams. An advertisement of Fair \& Lovely which is available on different social media mentioned that using of Fair \& Lovely cream should give appliers at least three lighter shades within six weeks.

There is both past and current evidence that reveals that people having dark skin all over the world, involve in skin lightening practices [4-8]. However, the highest percentage of women using skin whitening products are Nigerian, (77\%) according to the WHO [9]. Second, $61 \%$ of Indian women use skin whitening products. Moreover, China and South Africa have percentages of 40 and 35 respectively. Each country has a different perception of skin complexion. In China, pure white skin treated as a symbol of beauty. In India, a lighter complexion stands for high caste [10]. Moreover, people with lighter skin have the principal characters in Bollywood movies (Indian movies) and characterize themselves as more educated and cleaner compared to the darker skinned people. In contrast to African American women, who want to be three shades lighter to look like African American personalities such as Beyoncé Knowles, people from India embody intelligence to one's skin color. The research found that lighter skinned men were viewed to be more intelligent, and lighter skinned women more attractive. Dark skinned men were seen as lacking intelligence and dark-skinned women were viewed as less beautiful [11]. In Southern Asian cultures, a person having a dark skin color is apparent as less powerful and less beautiful (Philips). People of darker skin would marry lighter skinned partners in an attempt to raise their social status. These days a beautiful skin has no limits and extends across race, sex, and all age groups [12]. Thompson and Keith [13] identify the relationship between gender, skin color and self-concept for men and women in the African American society and found that skin tone proved to have a significantly positive effect on self-efficacy of both men and women. However, they found no association between skin color and self-esteem in case of a woman having a higher socio-economic status. They also observed that there is a significant increase in self-efficacy for men as skin color lightens.

Charles [14] considered the Jamaican people for measuring the self-esteem level among the persons aged in the group of 13 to 37, including males and females. He found that the members in the non-bleaching group have slightly lower self-esteem mean score than the bleaching group. Hunter [15], focuses on skin color hierarchies and the understanding of skin color in the lives of African-American women and found that the lighter the skin tone having a higher level of education as well as income. However, only a minor percentage of African-American women are represented in the highest income level. Koubaa, et al. [16] consider the Chinese-Singaporean women in order to investigate the attitude towards beauty skin and the intention of buying the skin care products and observed that the cultural values turned out to be a significantly important factor for the attitude towards skin beauty. However, the attitude towards skin beauty is positively associated with the willingness of buying the skin care products. Hall [17] addresses the assimilation of African American into the American society and he proposed that the degree of assimilation is associated with the skin color. He mentioned that the darker skin would have the most difficulties assimilating in America. $\mathrm{He}$ also notes that when skin color is treated like any other psychological characteristic, full assimilation will be achievable. Rusmadi, et al. [18] assessed the skin lightening practice and health symptoms among female students in Malaysia and they found that the use of skin lightening products is common practice among selected students and they also observed that some of these products can cause skin problems such as skin peeling, acne, and itching.

Kouotou, et al. [19] shown that almost thirty percent of Cameroonian female university students were practicing skin whitening products however among them only 14 percent says that this practice to be a good one. They have pointed out that the need to harmonize the skin tone of the whole body is the main motivating factor of practicing skin whitening products. January, et al. [20] identify the prevalence and beliefs around use of skin lighteners among female university students at the University of Zimbabwe and their results reveal that 20 percent of University students of Zimbabwe used the skin lightening creams and more than 80 percent of the respondents preferred lighter skin tone, and $93.3 \%$ perceived light skin as a symbol of beauty, $65 \%$ as a sign of wealth and $23.3 \%$ as symbolizing power. There is a great lacking of research about the skin whitening in Bangladesh. This research will provide a bridge to the researcher as well as consumers and producers of skin whitening products in Bangladesh. Therefore, this paper attempts to examine the influence of different factors on the attitude towards skin whitening products and the consumption relating to skin whitening products among the female students of Mathematical and Physical Science faculty of Jahangirnagar University, Bangladesh.

\section{Materials and Methods}

A self-administered questionnaire was used to collect the data from the respondents to study the attitude of the respondent about skin whitening and gather the information related to the practice of skin lightening, the knowledge, and also the perception about having white skin. The sample size is determined by $z=\frac{p q z^{2}}{d^{2}}=\frac{0.5 * 0.5 *(1.96)^{2}}{(0.05)^{2}}=384.16 \approx 385$ where $\quad p=$ 


\section{Epidemiology International Journal}

proportion of the female students uses skin whitining products (author has no previous information so use 0.5 since it gives the maximum number of sample size), $q=(1-p), z=$ standard value of normal statistics, at 5 percent level of significance the value of $z$ is 1.96 and $d=$ margin of error (here $5 \%$ is considered). Therefore, a total of 385 respondents were taken by using a non-probability convenience sampling procedure since all femele students were not willing to percipate in the study from the different department of Mathematical and Physical Science faculty of
Jahangirnagar University. A study was carried out from February to March 2018. It is generally believed that women have higher rates of skin lightening practice than men. For this reason, this study only focuses on female students. The socio-demographic information and the skin lightening practice are presented by descriptive analysis. The statistical analysis is conducted by IBM SPSS Statistics 24.0 (SPSS Inc., Chicago, IL, USA). The location map of the study area for this study is presented in Figure 1.

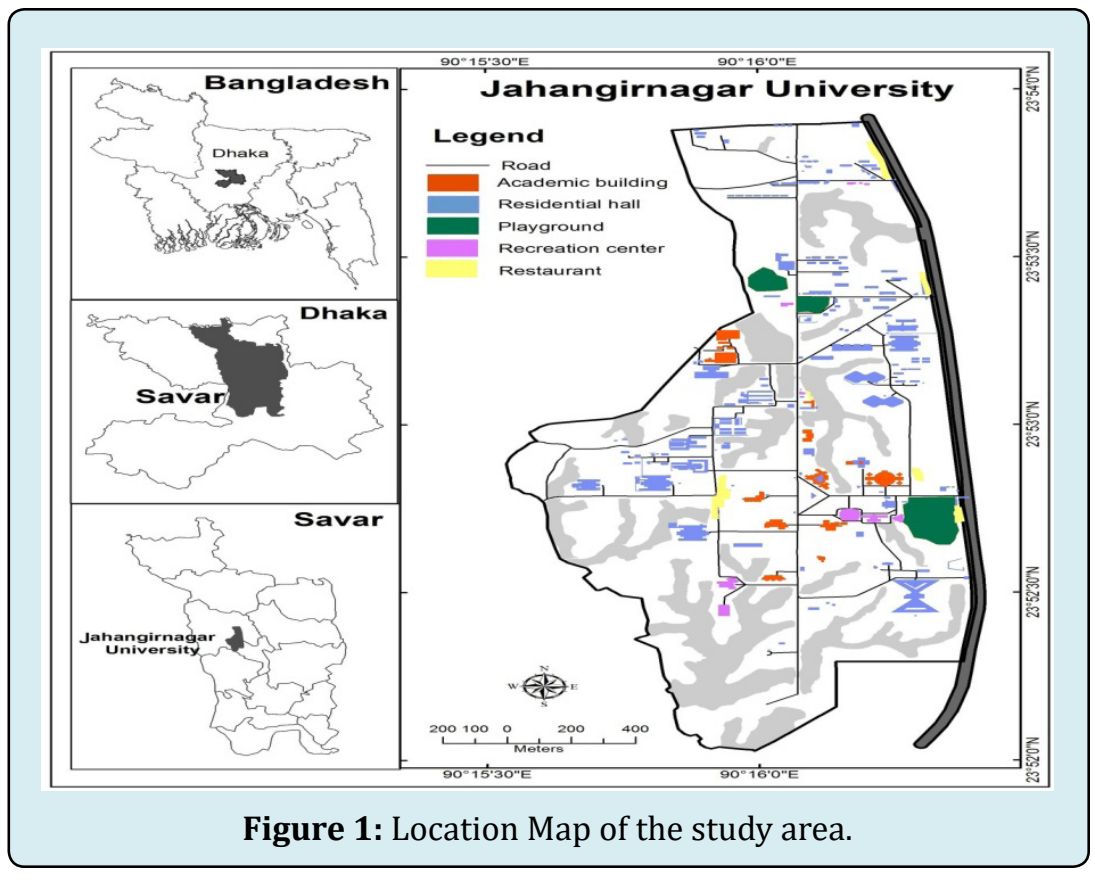

\section{Results}

At first the author find the Cronbach's alpha in order to check the reliability and here the value is 0.837 which is more than the acceptance level. This study involved 385 respondents from the seven departments under the faculty of Mathematical and Physical Sciences of Jahangirnagar
University. Here, the equal allocation of the sample is used that is from each department a total of 55 undergraduate students and postgraduate students is selected. The highest number of respondents $(23.4 \%)$ were from the fourth year of Bachelor of Science whereas the lowest (14.0\%) from masters (Table 1). However, all the remaining academic year the percentages of the respondents are about 20 .

\begin{tabular}{|c|c|c|c|c|c|c|c|c|}
\hline \multirow{2}{*}{$\begin{array}{c}\text { Academic } \\
\text { Year }\end{array}$} & \multicolumn{7}{|c|}{ Department } & \multirow{2}{*}{ Total (\%) } \\
\cline { 2 - 9 } & Statistics & Mathematics & Physics & Chemistry & CSE & $\begin{array}{c}\text { Geological } \\
\text { Science }\end{array}$ & $\begin{array}{c}\text { Environmental } \\
\text { Science }\end{array}$ & 10 \\
\hline First Year & 12 & 11 & 18 & 9 & 8 & 11 & 10 & $79(20.5)$ \\
\hline Second Year & 15 & 10 & 8 & 12 & 15 & 8 & 12 & $80(20.8)$ \\
\hline Third Year & 6 & 11 & 13 & 11 & 12 & 16 & 13 & $82(21.3)$ \\
\hline Fourth Year & 13 & 15 & 9 & 14 & 15 & 15 & 9 & $90(23.4)$ \\
\hline Masters & 9 & 8 & 7 & 9 & 5 & 5 & 11 & $54(14.0)$ \\
\hline Total & 55 & 55 & 55 & 55 & 55 & 55 & 55 & $385(100.0)$ \\
\hline
\end{tabular}

Table 1: Frequency Distribution of the Respondents by Year and Department. 


\section{Epidemiology International Journal}

The following figure (Figure 2) depicts the histogram of the age of the selected students for this study. It is observed that the average age is just under 22 years with a standard deviation of 1.69 years. The age of the participated students was between 17 and 25 years. Also, most of the student's age between 20 and 25 years.

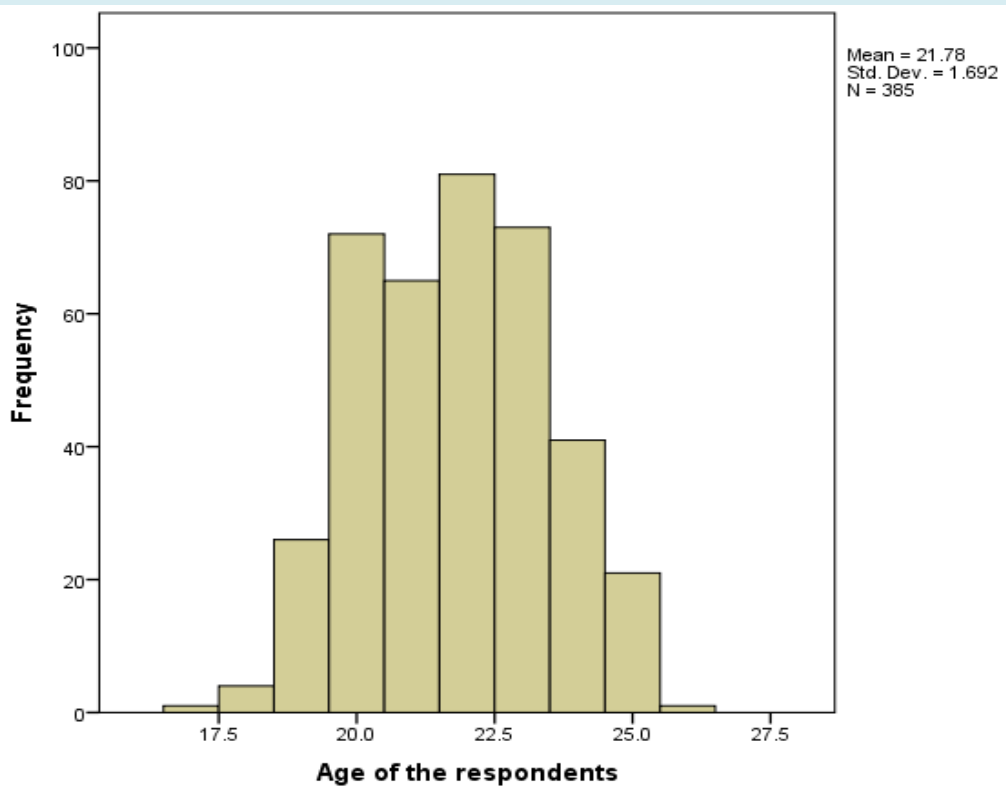

Figure 2: Histogram of the age of the respondent.

The results given in Table 2 shows that only about 30 percent of students feel that skin whitening is a good practice. However, the majority of the students having the opposite opinion about this statement. Though only 30 percent of students agreed that the use of skin whitening product is a good practice but more than 55 percent of students use the skin lightening/whitening products.

\begin{tabular}{|c|c|c|c|}
\hline \multirow{4}{*}{ Whether skin whitening is a good practice } & & Frequency & Percent \\
\hline & Yes & 120 & 31.2 \\
\hline & No & 265 & 68.8 \\
\hline & Total & 385 & 100.0 \\
\hline \multirow{3}{*}{ Whether use skin lightening products } & Yes & 215 & 55.8 \\
\hline & No & 170 & 44.2 \\
\hline & Total & 385 & 100.0 \\
\hline
\end{tabular}

Table 2: Frequency distribution of the opinion of skin whitening.

Figure 3 highlights the meaning of skin lightening given by the responded female students in this study. In this case, we observed multiple responses. It can be said that among 385 respondents, 245 students say that skin whitening means changing the skin color from black to white whereas about 75 percent respondents provide the opinion that skin whitening means removing marks from the skin or making the skin more vivid and radiant. Also, 285 female students say that skin whitening means removing the marks from their skin. Moreover, another opinion is that cleaning the skin deeply indicates skin whitening. 


\section{Epidemiology International Journal}

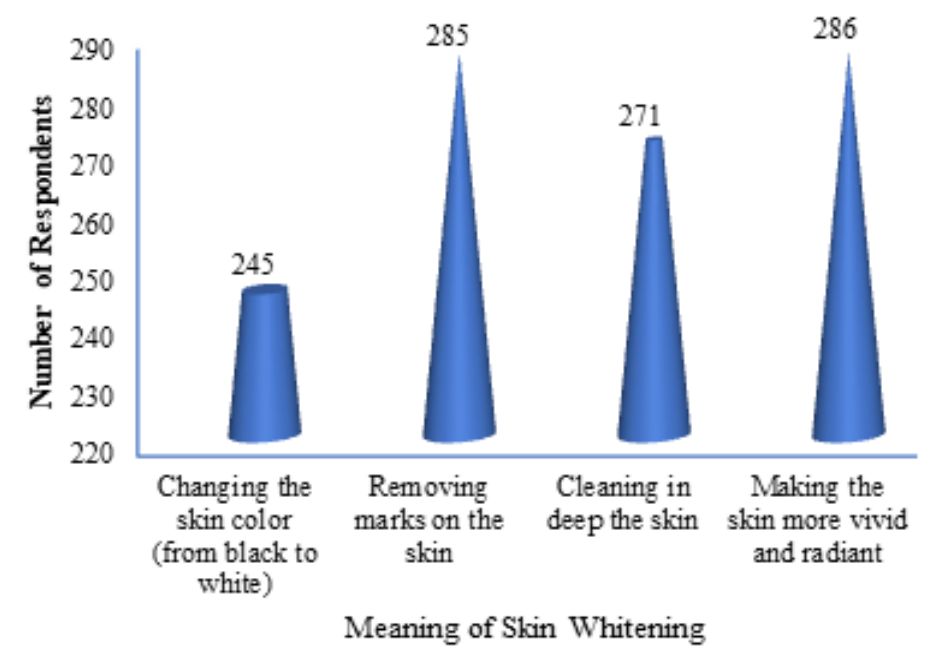

Figure 3: Meaning of Skin Whitening.

Table 3 represents the characteristics of the beautiful skin given by the female students considered in this study. Based on the respondents who answer with "Yes" to the characteristics of beautiful skin. The results depict that overall more than 90 percent of female students think that beautiful skin means smooth skin. Also near about all students from the Department of Physics and CSE says that smooth skin is the symbol of beautiful skin. However, approximately three-quarter of the respondents lighter skin is the characteristics of beautiful skin. Furthermore, four out of five students having an opinion that without any wrinkle or mark is the characteristics of the beautiful skin.

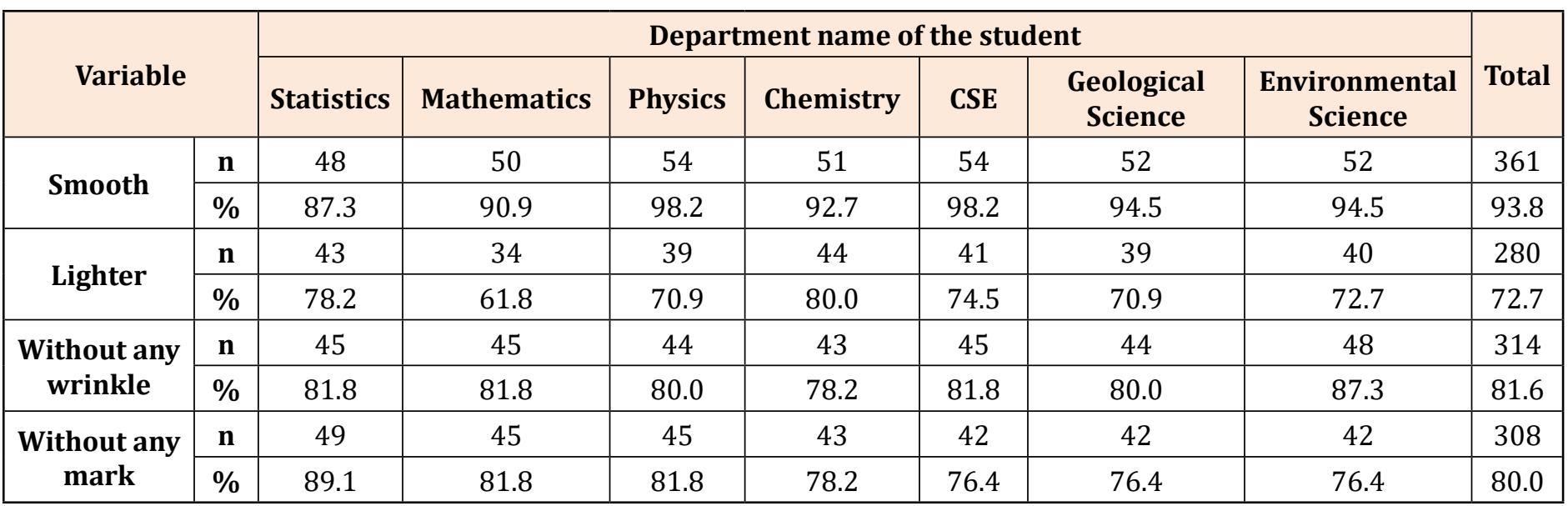

Table 3: Frequency Distribution of the Characteristics of Beautiful Skin.

Table 4 represents the skin lightening/whitening practice among female students in this study. According to the respondents who use skin whitening products, fruits are the most common type of product used $(n=179,83 \%)$ followed by facial cleanser ( $\mathrm{n}=155,72 \%)$. Others types of products used are facial moisturizer $(\mathrm{n}=143,66 \%)$, sunblock or serum ( $\mathrm{n}=118,55 \%)$, facial mask ( $\mathrm{n}=106,49 \%)$, antiseptic soap $(n=91,42 \%)$, toner $(n=77,35 \%)$ and anti-aging $(n=36$, $16 \%)$. Friends or the entourage (76\%) is the most influential factor to encourage purchasing skin whitening products. Also, Brand influence (71\%), media (71\%) and relatives (71\%) are the other main influential factors that were considered the most in the skin lightening product selection. However, a reasonable price in this study was less likely being considered by the respondent (44\%). The most common place to purchase the product in this study is in Specialty beauty store ( $\mathrm{n}=137,63 \%)$, followed by Convenience shop $(\mathrm{n}=108,50 \%)$, Department store $(\mathrm{n}=97,45 \%)$, Drugstore 


\section{Epidemiology International Journal}

$(\mathrm{n}=83,38 \%)$ and Online $(52,24 \%)$.

\begin{tabular}{|c|c|c|c|c|c|}
\hline \multirow{2}{*}{\multicolumn{2}{|c|}{ Variable }} & \multicolumn{2}{|c|}{ Yes } & \multicolumn{2}{|c|}{ No } \\
\hline & & \multirow{2}{*}{$\begin{array}{c}\text { Frequency } \\
179\end{array}$} & \multirow{2}{*}{$\begin{array}{c}\text { Percent } \\
83.26\end{array}$} & \multirow{2}{*}{$\begin{array}{c}\text { Frequency } \\
36\end{array}$} & \multirow{2}{*}{\begin{tabular}{r|} 
Percen \\
16.74
\end{tabular}} \\
\hline \multirow{8}{*}{ Types of products used } & $\begin{array}{c}\text { Fruits (lemon, cucumber, } \\
\text { carrot...) }\end{array}$ & & & & \\
\hline & Antiseptic soap & 91 & 42.33 & 124 & 57.67 \\
\hline & Facial cleanser & 155 & 72.09 & 60 & 27.91 \\
\hline & Facial mask & 106 & 49.30 & 109 & 50.70 \\
\hline & Facial moisturizer & 143 & 66.51 & 72 & 33.49 \\
\hline & Antiaging & 36 & 16.74 & 179 & 83.26 \\
\hline & Toner & 77 & 35.81 & 138 & 64.19 \\
\hline & Others (sunblock, serum) & 118 & 54.88 & 97 & 45.12 \\
\hline \multirow{7}{*}{$\begin{array}{l}\text { Factors considered during } \\
\text { purchasing }\end{array}$} & The medias & 153 & 71.16 & 62 & 28.84 \\
\hline & Relatives & 153 & 71.16 & 62 & 28.84 \\
\hline & Ingredient used & 121 & 56.28 & 94 & 43.72 \\
\hline & Reasonable price & 96 & 44.65 & 119 & 55.35 \\
\hline & Brand influence & 154 & 71.63 & 61 & 28.37 \\
\hline & Men & 135 & 62.79 & 80 & 37.21 \\
\hline & Friends/the entourage & 165 & 76.74 & 50 & 23.26 \\
\hline \multirow{5}{*}{ Point of purchase } & Department store & 97 & 45.12 & 118 & 54.88 \\
\hline & Specialty beauty store & 137 & 63.72 & 78 & 36.28 \\
\hline & Drugstore & 83 & 38.60 & 132 & 61.40 \\
\hline & Online & 52 & 24.19 & 163 & 75.81 \\
\hline & Convenience shop & 108 & 50.23 & 107 & 49.77 \\
\hline
\end{tabular}

Table 4: The skin whitening practice among female students $(n=215)^{1}$

Note: ${ }^{1}$ person who answers with "Yes" to skin lightening product use. Also, provide multiple answer

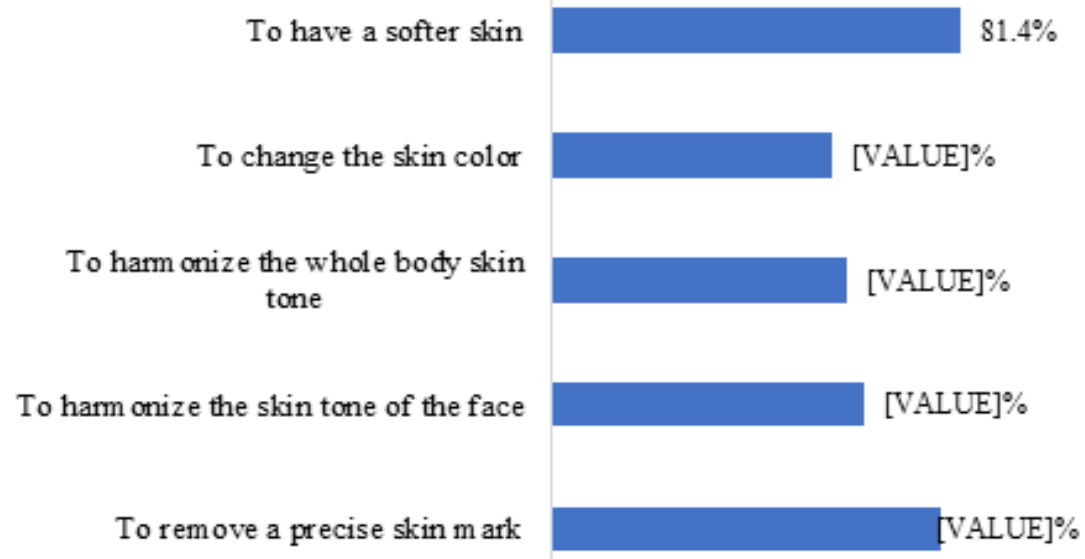

Figure 4: Motivations supporting the practice of skin whitening. 


\section{Epidemiology International Journal}

Figure 4 illustrates the reasons for motivating the practice of skin whitening. Among the factors force to use skin whitening products, the desire for a softer skin was the prevailing reason $(81.4 \%)$, followed by the desire for removing a precise skin marks $(77.21 \%)$. The desire to change the skin color was the least encountered motivation (55.81\%). However, about 60 percent of the female students say that they are motivated to use the skin whitening products because of harmonizing the skin tone of the whole body as well as their face.

Table 5 shows the skin problems experienced by the respondents. About 40 percent of respondents in this study had a skin problem from the application of skin lightening products. Out of 88 respondents who had a skin problem from lightening product application, the majority of them had skin irritation (68\%) and spot (61\%). Another two problems were pruritus (36\%) and burning (29\%).

\begin{tabular}{|c|c|c|c|c|c|}
\hline \multicolumn{2}{|c|}{ Variable } & \multicolumn{2}{c|}{ Yes } & \multicolumn{2}{c|}{ No } \\
\cline { 2 - 6 } & & Frequency & Percent & Frequency & Percent \\
\hline \multirow{2}{*}{ Skin problem caused by skin lightening products } & 88 & 40.93 & 127 & 59.07 \\
\hline \multirow{3}{*}{$\begin{array}{c}\text { Type of skin } \\
\text { problem }\end{array}$} & Irritation (feeling annoyed) & 60 & 68.18 & 28 & 31.82 \\
\cline { 2 - 6 } & Pruritus (sever eitching of the skin) & 32 & 36.36 & 56 & 63.64 \\
\cline { 2 - 7 } & Burning & 26 & 29.55 & 62 & 70.45 \\
\cline { 2 - 7 } & Spot & 54 & 61.36 & 34 & 38.64 \\
\hline
\end{tabular}

Table 5: Skin problems experienced by respondents $(n=215)^{2}$.

Note: ${ }^{2}$ person who answers with "Yes" to skin problem cause by skin lightening products.

Figure 5 shows the result of the respondent's perception with regard to skin lightening practice. Among, 385 respondents, more than three-quarter of the respondent having a perception that their counterpart considers them with lighter skin is to be more beautiful. Another three important factors are lighter skin increase the likelihood of getting married, more beautiful and look healthier and provide higher self-esteem. However, only 34 percent respondent think that lighter skin helps to get a better job. Also, among the female students considered in this study, 139 respondents have an opinion that lighter skin implies belonging to a higher social class.

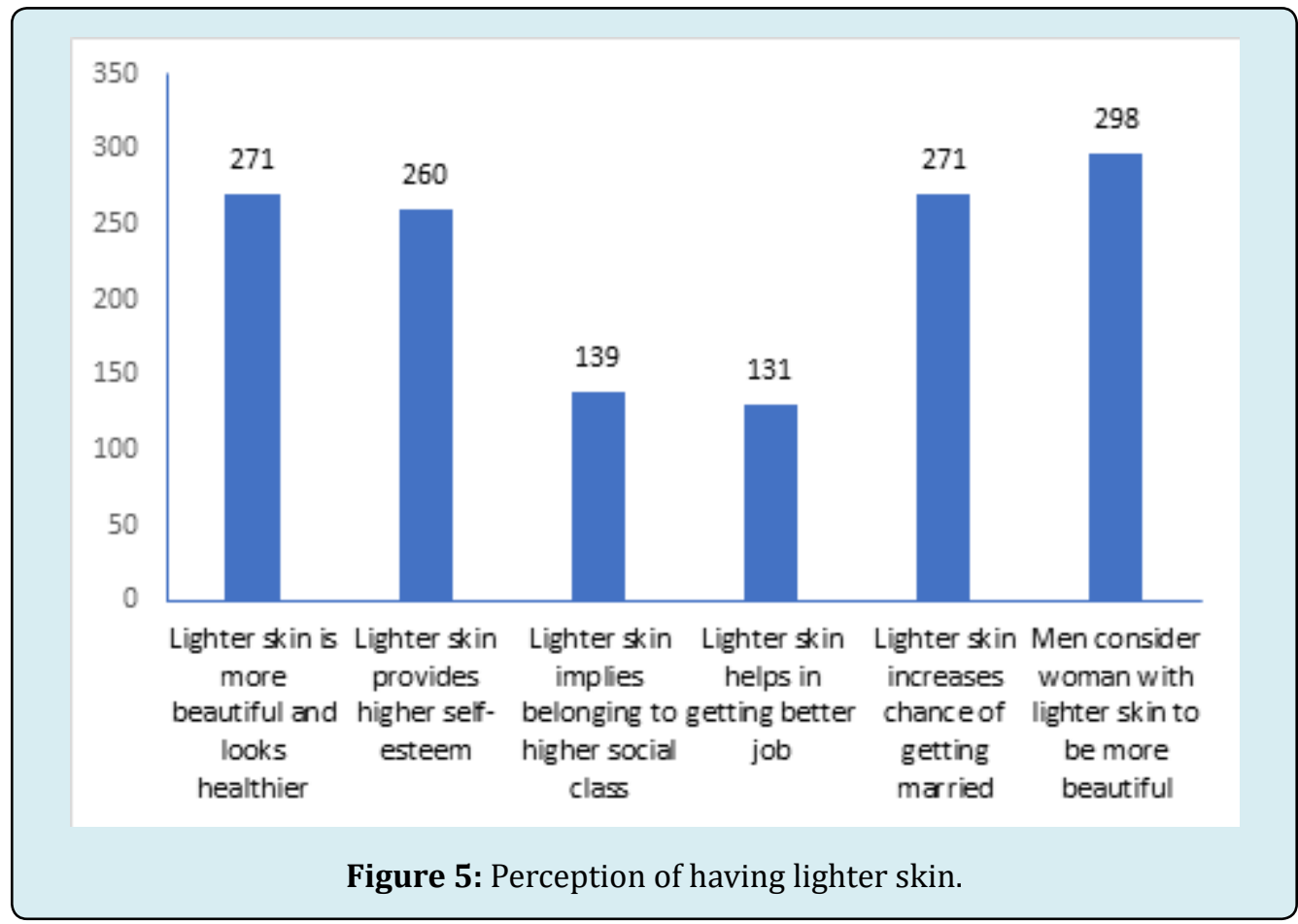

Md Moyazzem Hossain. Attitudes of the Female University Students towards Skin Whitening in Bangladesh. Epidemol Int J 2020, 4(1): 000134. 


\section{Epidemiology International Journal}

\section{Discussion}

According to The Guardian [21], the prolonged use of mercury and hydroquinone are linked to poisoning, skin damage and liver and kidney malfunction and corticosteroids. Also, the misuse of corticosteroid creams is associated with thinning of the skin, an increased chance of skin cancer and, counterintuitively, darkening of the skin.

In our survey, the respondent's ages ranged from 17 to 25 years (mean approximately 22 years) comparable to results from Kouotou, et al. [19] and Traoré, et al. [22]. The results indicate that the minority of the students agreed that the use of skin whitening product is a good practice this result is consistent with Kouotou, et al. [19] but some students reports that they had a skin problem from the application of skin lightening products like skin irritation, spot, pruritus and burning these results are similar to Rusmadi, et al. [18]. The majority of the respondent having a perception that their counterpart consider them with lighter skin is to be more beautiful. Another three important factors are lighter skin increase the likelihood of getting married, more beautiful and look healthier and provide higher self-esteem also supported by Rusmadi, et al. [18]. However, some respondents think that lighter skin helps to get a better job.

This study used convenience sampling which is one of the limitations of the study. This might have resulted in a study population which might not have been representative enough for the whole female university students of Bangladesh. Again, this study considers only one university. Thus, there is a need for future studies to incorporate findings from all universities in Bangladesh and generalize for all female university students in Bangladesh. However, the present study is worthwhile in providing preliminary evidence and insights on the use of skin whiteners among university students in Bangladesh, to inform future larger studies on this area.

\section{Conclusion}

The cosmetic manufacturers have a responsibility to ensure that their consumers are aware of the skin care products. As technologies continue to improve and revolutionary new skin care products and treatments are presented, academic institutions and industries may arrange several seminars, workshops and conferences for faculty and students so that they are able to enrich their knowledge about such products.

Despite knowing and being aware of the danger of skin lightening products, it is not possible to stop them from using it as they believe that having a lighter skin tone is for their own self-satisfaction. By understanding the important factors that influence both the attitude and consumption regarding skin whitening products, marketers will position and advertise the skin whitening products. The factors may have a different effect in terms of implication and extent on the attitude and consumption regarding skin Whitening products. This study will be used to increases the awareness of skin whitening products.

\section{Ethical Approval and Consent to Participate}

This study was conducted while maintaining ethical standards to the highest possible extent. All participants read, understood, and signed a written consent form. The ethical clearance for data collection was given by the Jahangirnagar University.

\section{Consent for Publication}

All participants read, understood, and signed a written consent form for publishing the results and figures by analyzing the raw data without specified information like name. The authority of Jahangirnagar University who give permission to publish the findings in the journal.

\section{Acknowledgment}

Authors are grateful to the University Grants Commission, Bangladesh via Faculty of Physical and Mathematical Sciences, Jahangirnagar University for providing partial financial support in order to conduct this research. The author would like to give thanks to Sahadat Hossain, Department of Public Health and Informatics, Jahangirnagar University, Bangladesh for the location map of the study area. Authors are very much grateful to the Editors as well as anonymous reviewers for carefully examine the manuscript and their valuable comments and suggestions which is helpful to improve the quality of this paper.

\section{References}

1. Mire A (2012) The Scientification of Skin Whitening and the Entrepreneurial University-Linked Corporate Scientific Officer. Canadian Journal of Science, Mathematics and Technology Education 12(3): 272-291.

2. Askari SH, Sajid A, Faran Z, Sarwar SZ (2012) SkinLightening Practice among Women living in Lahore: Prevalence, Determinants, and User's Awareness, University of Engineering and Technology Lahore, pp: 1-14.

3. Karnani A (2007) Doing well by doing good - Case Study: Fair \& Lovely whitening cream. Strategic Management Journal 28: 1351-1357. 


\section{Epidemiology International Journal}

4. Desmedt B, Van Hoeck E, Rogers V, Courselle P, DeBeer J, et al. (2014) Characterization of suspected illegal skin whitening cosmetics. J Pharm Biomed Anal 90: 85-91.

5. Gupta AK, Gover MD, Nouri K, Taylor S (2006) The treatment of melasma: A review of clinical trials. Journal of the American Academy of Dermatology 55(6): 10491065.

6. Lartey M, Krampa FD, Abdul-Rahman M, Quarcoo NL, Yamson P, et al. (2016) Use of skin lightening products among selected urban communities in Accra, Ghana. Int J Dermatol 56(1): 32-39.

7. Leong $S$ (2006) Who's the fairest of them all? Television ads for skin-whitening cosmetics in Hong Kong. Asian Ethnicity 7(2): 167-181.

8. Mendoza RL (2014) The skin whitening industry in the Philippines. J Public Health Policy 35(2): 219-238.

9. World Health Organization (WHO) 2012 Preventing disease through healthy environments, Switzerland.

10. Li EPH, Min HJ, Belk RW, Kimura J, Bahl S (2008) Skin Lightening and Beauty in Four Asian Cultures. In: Lee AY, Soman D, Duluth MN (Eds.), Advances in Consumer Research. Association for Consumer Research, pp: 444449.

11. Glenn EN (2008) Yearning for Lightness: Transnational Circuits in the Marketing and Consumption of Skin Lighteners. Gender \& Society 22(3): 281-302.

12. Souza de MM (2008) The concept of skin bleaching in Africa and its devastating health implications. Clinic Dermatol 26(1): 27-29.

13. Thompson MS, Keith VM (2001) The Blacker the Berry: Gender, Skin Tone, Self-Esteem and Self-Efficacy. Gender \& Society 15(3): 336-357.
14. Charles CAD (2003) Skin Bleaching, Self-Hate, and Black Identity in Jamaica. Journal of Black Studies 33(6): 711728.

15. Hunter ML (1998) Colorstruck: Skin Color Stratification in the Lives of African American Women. Sociological Inquiry 68(4): 517-535.

16. Koubaa Y, Ulvoas G, Chew P (2011) The dual impact of traditional and national cultural values on expatriate ethnic groups' attitudes and willingness to buy. Asia Pacific Journal of Marketing and Logistics 23(5): 626640.

17. Hall R (1995) The Bleaching Syndrome: African Americans' Response to Cultural Domination Vis-a-Vis Skin Color. Journal of Black Studies 26(2): 172-184.

18. Rusmadi SZ, Ismail SNS, Praveena SM (2015) Preliminary Study on the Skin Lightening Practice and Health Symptoms among Female Students in Malaysia. J Environ Public Health.

19. Kouotou EA, Nansseu JRN, Adegbidi H, Mebara TCJZ, Ndam ECN (2017) Skin whitening among Cameroonian female university students: knowledge, attitudes, practices and motivations. BMC Women's Health 17: 33.

20. January J, Mberi YT, Muchenje RR, Gonah L, Shamu S, et al. (2018) Use of skin lightening creams among female University students in Zimbabwe: a preliminary survey. Medical Journal of Zambia 45(1): 44-48.

21. The Guardian (2018) Skin-lightening creams are dangerous-yet business is booming. Can the trade be stopped?

22. Traore A, Kadeba JC, Niamba P, Barro F, Ouedraogo L (2005) Use of Cutaneous depigmenting products by women in two towns in Burkina Faso: Data, motivations, products and side effects. Int J Dermatol 44(1): 30-32.

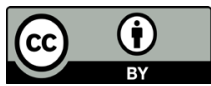

